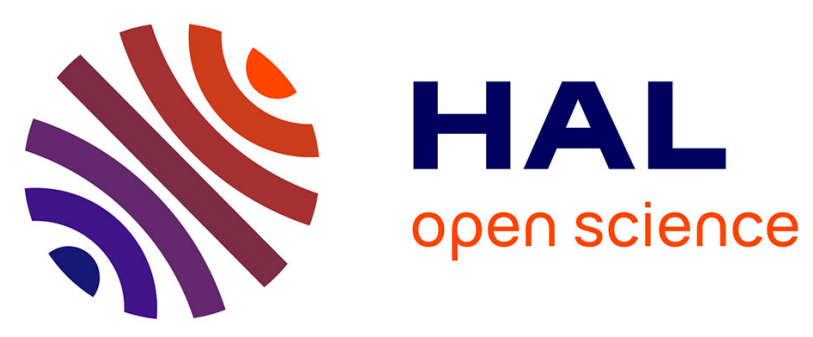

\title{
PREV'AIR : an operational forecasting and mapping system for air quality in Europe
}

Laurence Rouil, Cécile Honore, Robert Vautard, Matthias Beekmann, Bertrand Bessagnet, Laure Malherbe, Frédérik Meleux, Anne Dufour, Christian Elichegaray, Jean-Marie Flaud, et al.

\section{To cite this version:}

Laurence Rouil, Cécile Honore, Robert Vautard, Matthias Beekmann, Bertrand Bessagnet, et al.. PREV'AIR : an operational forecasting and mapping system for air quality in Europe. Bulletin of the American Meteorological Society, 2009, 90 (1), pp.73-83. 10.1175/2008BAMS2390.1 . ineris00961933

\section{HAL Id: ineris-00961933 \\ https://hal-ineris.archives-ouvertes.fr/ineris-00961933}

Submitted on 20 Mar 2014

HAL is a multi-disciplinary open access archive for the deposit and dissemination of scientific research documents, whether they are published or not. The documents may come from teaching and research institutions in France or abroad, or from public or private research centers.
L'archive ouverte pluridisciplinaire HAL, est destinée au dépôt et à la diffusion de documents scientifiques de niveau recherche, publiés ou non, émanant des établissements d'enseignement et de recherche français ou étrangers, des laboratoires publics ou privés. 


\title{
PREV'AIR \\ An Operational Forecasting and Mapping System for Air Quality in Europe
}

\author{
by Laurence Roull, Cécile Honoré, Robert Vautard, Matthias Beekmann, Bertrand Bessagnet, \\ Laure Malherbe, Frédérik Meleux, Anne Dufour, Christian Elichegaray, Jean-Marie Flaud, \\ Laurent Menut, Daniel Martin, Aline Peuch, Vincent-Henri Peuch, and Nathalie Poisson
}

Advanced chemistry-transport modeling and observing systems allow daily air quality observations, short-term forecasts, and real-time analyses of air quality at the global and European scales, with a focus over France.

$\mathrm{T}$ he heat wave that struck western Europe in August 2003 was not only extreme in temperature but also in the persistence of high ozone concentrations for almost 3 weeks. During the heat wave, the Europe-wide photochemical episode (Vautard et al. 2005) that developed contributed to an increase of mortality resulting from respiratory disease, as demonstrated by the health community (WHO 2005; Schlink et al. 2006; Stedman 2005; Parodi et al. 2005). In response to the challenge of anticipating efficient control measures that could be taken for managing such episodes, European-scale air quality forecasting systems are developed. The French air quality fore- casting and mapping system (PREV'AIR) is the result of one of these initiatives. It was made operational in France in the spring of 2003. During the August 2003 heat wave, it ran every day, allowing for anticipation of the spatial and temporal evolution of the ozone concentrations, and the public was kept informed. Considering the benefits of this experience, French legislation has been adapted in such a way that the local authorities in charge of air pollution can now inform the public and take emergency decisions related to air pollution control not only on the basis of measurements, but also by accounting for numerical forecasts. PREV'AIR has become a part of the national
Affiliations: Rouil, Honoré, Bessagnet, Malherbe, and MeleuX-Direction des Risques Chroniques, Institut National de I'Environnement Industriel et des Risques, Verneuil en Halatte, France; VAUTARD - Laboratoire des Sciences du Climat et de I'Environnement, Institut Pierre Simon Laplace, Gif-sur-Yvette, France; BeEkMANN AND FLAUD-Faculté des Sciences et Technologies, Laboratoire Inter-Universitaire des Systèms Atmosphériques, Créteil, France; Menut—Laboratoire de Météorologie Dynamique, Institut Pierre Simon Laplace, Ecole Polytechnique, Palaiseau, France; Dufour, Martin, A. Peuch, and V.-H. Peuch-MétéoFrance, Paris, France; Elichegaray AND PoIsson-Agence de l'Environnement et de la Maîtrise de l'Energie, Angers, France.
CORRESPONDING AUTHOR: Laurence Rouil, INERIS, Chronic Risks Division, Parc technologique Alata, BP2, Verneuil-en-Halatte, F-60550, France

E-mail: laurence.rouil@ineris.fr

The abstract for this article can be found in this issue, following the table of contents.

DOI:10.1175/2008BAMS2390.1

In final form 7 May 2008

@2009 American Meteorological Society 
air quality monitoring system. In case of a pollution episode, when concentrations exceed the regulatory thresholds, PREV'AIR forecasts are broadcast on television channels to enhance public information. It delivers everyday forecasts and near-real-time information related to ozone, nitrogen dioxide, and particulate matter concentrations throughout western Europe and France. Analyzed maps and numerical data are available online (see www.prevair.org).

Three main objectives of PREV'AIR are 1) to provide a powerful communication tool to inform the public and sensitive population about the potential occurrence of pollutant concentrations exceeding regulatory thresholds, 2) to offer technical support for authorities in charge of air pollution to decide and apply emergency control measures before the pollution event, especially related to road traffic and industry, and 3) to contribute to a better understanding of these situations.

The ability of regional three-dimensional air quality models to predict air quality has been demonstrated in several instances (Vautard et al. 2001; Tilmes et al. 2002; Otte et al. 2005; McKeen et al. 2005). Therefore, recently, several other air quality forecasting systems running routinely have been developed in Europe (see, e.g., www.eurad.uni-koeln. de), in the United States, and in Canada (see www. nws.noaa.gov/aq and www.weatheroffice.gc.cal chronos/index_e.html, respectively). Evaluation of such systems show relevant performances (Eder et al. 2006; Honoré et al. 2008). However, PREV'AIR is unique for two main reasons. First, it is the result of a cooperative initiative organized under the supervision of the French Ministry in charge of ecology and sustainable development, between the following four organizations that gather skills and experience in complementary domains: the Agency of Environment [Agence de l'Environnement et de la Maîtrise de l'Energie (ADEME)], the National Research Centre [Centre National de la Recherche Scientifique (CNRS)], the National Institute for Industrial Risks and Environment [Institut National de l'Environnement Industriel et des Risques (INERIS)], and the National Weather Services (Météo-France). Second, PREV'AIR has become an operational communication tool for authorities, the media, and the public to deal with strong air pollution episodes. It also provides technical data (such as boundary conditions) to local air quality monitoring systems. For these reasons, PREV'AIR partners have to deal with strong operational constraints regarding the availability on time of the forecasts and the reliability and the quality of the products delivered.

This article aims at giving a digest presentation of the PREV'AIR platform, and a synthesis of its predicting skill [for an extensive presentation of the system performance, see Honoré et al. (2008)]. A general description of the tools and the models is given in the next section. Then, technical information related to the results obtained since 2003 and the performances reached, is proposed in "PREV'AIR products." Finally, conclusions are drawn, focused on the relevance of extending the PREV'AIR concept to build a wider European air quality monitoring service. Such an initiative is now planned by the European Commission in the Global Monitoring for Environment and Security (GMES) program (online at www.gmes.info), and its feasibility study is demonstrated by PREV'AIR.

SYSTEM DESCRIPTION. What is delivered? PREV'AIR relies on a chain of numerical tools: air quality simulation models, modules ensuring the provision of meteorological and air quality input data to these models, and modules enabling the extraction and use of the numerical data computed by the system. Figure 1 illustrates how the three main functions of the PREV'AIR system-forecasting, analysis, and performance evaluation-are organized. Input and output flows are detailed.

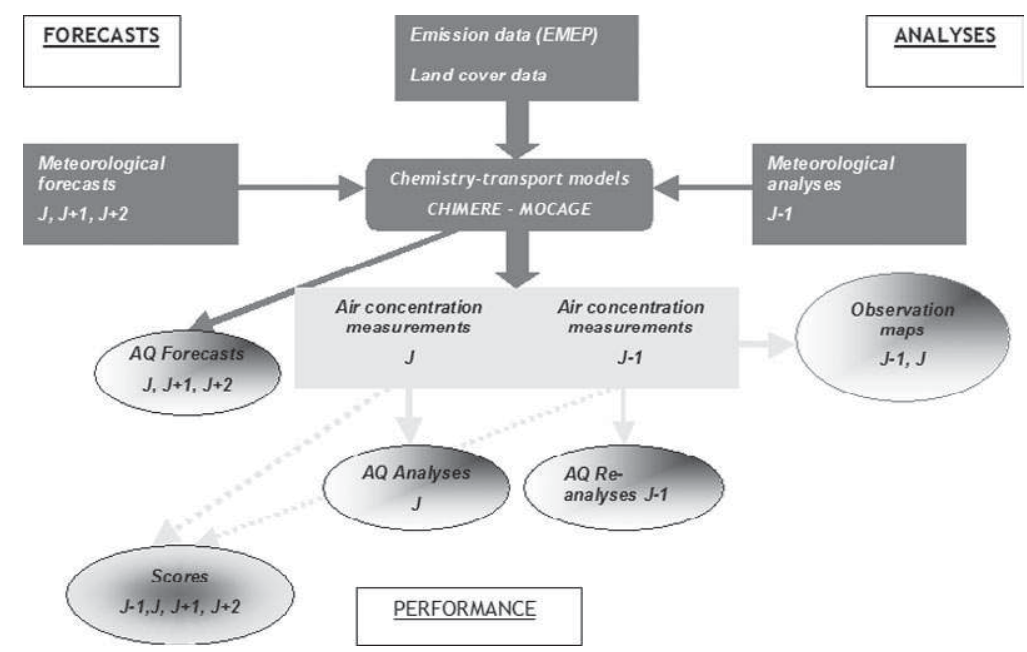

FIG. I. General diagram of the PREV'AIR system: a clear distinction is made between forecasting and mapping abilities of the system. Input and output flows are detailed. 
1) The "forecasting" function delivers forecasted atmospheric concentrations of ozone, particulate matter (PM10 and PM2.5), and nitrogen oxides, simulated throughout Europe at low resolution $\left(0.5^{\circ} \times 0.5^{\circ}\right)$ and over France with a higher resolution $\left(0.15^{\circ} \times 0.1^{\circ}\right)$. At the global scale, forecasts of ozone, nitrogen dioxide, and dust concentrations are also available with a $2^{\circ}$ resolution. Forecasts with lead times up to 2 days ahead are presented each day.

2) The "analysis" process uses available near-realtime observations to build the "analyzed" maps that are considered as the most realistic description of pollution patterns. These analyses are simulations corrected by observations, and are processed for ozone and PM10 concentrations. This option is operational for France thanks to a near-real-time observation database (named BASTER), which, with a 3 -h frequency, gathers all measurements made on an hourly basis by the local air quality networks. Extension of the analyses with observations from Germany, Italy, Finland, Austria, and the United Kingdom is being implemented.

3) The "performance evaluation" function of the system uses observation data that are routinely acquired for continuous evaluation of the model forecasts, with descriptive indicators given online. Every day, statistical skill scores (bias, errors, percentage of errors lower than a certain level, and correlation) are calculated and updated on the PREV'AIR Web site.

PREV'AIR is becoming a successful experience in the European air quality community because it is a user-oriented product. The system not only provides colored figures as proposed on its Web site, but also supplies numerical data on user accounts. Up to now, about 50 French and European users' accounts are managed by PREV'AIR. The users can ask for an extraction of numerical data over a geographical domain that they define. Numerical data are either surface data (ground-level concentrations) or three-dimensional fields that will be used as boundary conditions of local-scale modeling systems. In that case, in addition to ozone, nitrogen oxides, and PM10 and PM2.5 fields, concentrations of ozone precursors [volatile organic compounds (VOC)] and PM components (seven species) are available. The users have a dedicated space on a nonpublic part of the PREV'AIR Web site. They can download the data they require, have technical exchanges with the PREV'AIR team, and express their point of view about the quality of the PREV'AIR products. The registration of PREV'AIR users is managed through registration files that are downloadable on the Web site. Moreover, the users can get access to the entire private part of the PREV'AIR system where sensitivity tests and performance skills are performed and proposed.

From 1 June to 15 September, when ozone episodes may occur, PREV'AIR is run in a fully operational mode, with 24/24 and 7/7 days turns to guarantee that no failure in the system could prevent the provision of the outputs on the Web site and in the user's accounts.

Finally, PREV'AIR outputs (forecasts and analyzed maps) are archived to build up a large air quality simulation database for Europe. Simulations are now available since 2003. This database should be of great interest to compute budgets and trend analyses for ozone and PM concentrations. This kind of result could be crucial for the evaluation of the European Air Quality Directives implementation or their review.

The PREV'AIR components. The core of the system consists of three-dimensional deterministic models dedicated to air quality simulation/forecast (Fig. 1). Currently, the following two models have been implemented within PREV'AIR:

- The CHIMERE model, described both in several papers (see, e.g., Schmidt et al. 2001; Bessagnet et al. 2004) and online (http://euler.Imd.polytechnique. fr/chimere/), has been evaluated and intercompared with other models for ozone and PM10 simulation in several studies (Vautard et al. 2006; Van Loon et al. 2007). The model is operated at INERIS.

- The Modéle pour la Chimie Atmosphérique Grand Echelle (MOCAGE) has been developed since 1998 by the French National Meteorological Research Center of Météo-France (Peuch et al. 1999; Dufour et al. 2004). Within the operational framework of PREV'AIR, the MOCAGE calculations, including ARPEGE and ALADIN meteorological calculations, are carried out by Météo-France on their operational site; the numerical data files are then automatically retrieved and postprocessed by PREV'AIR.

Both models take into account gaseous photochemistry. Concerning aerosols, CHIMERE delivers particulate matter forecasts, while MOCAGE provides dust forecasts. 
General comments about the models. Geometrical CONFIGURATION. The models are run at three different spatial scales-global, European, and metropolitan France. At the European scale, the horizontal resolution of both models is equal to $0.5^{\circ}$ (approximately $50 \mathrm{~km}$ ) in longitude and latitude; at the national scale resolution is $0.15^{\circ}$ in longitude and $0.1^{\circ}$ in latitude (approximately $10 \mathrm{~km}$ ). Only the MOCAGE model runs at the global scale, with a horizontal resolution of $2^{\circ}$. Along the vertical, from the surface up to $500 \mathrm{hPa}$, 20 levels are taken into account in MOCAGE versus the 8 levels in CHIMERE. In total, the operational version of MOCAGE has 47 hybrid (sigma, $P$ ) levels, with 27 additional ones covering the range from 500 to $5 \mathrm{hPa}$ (approximately $35 \mathrm{~km}$ ), while CHIMERE only represents the lower troposphere. Thus, unlike CHIMERE, MOCAGE is the only model that is able to represent the possible stratospheric contribution to the ozone levels in the troposphere and variations in the UV actinic fluxes resulting from variation in the ozone layer.

Meteorology. CHimere and MOCAGE are two "chemistry-transport models" ("CTM"): the meteorological input data required by these models are calculated offline by meteorological models. The CTM forecast are therefore applied downstream of meteorological forecasts, as described below. The analyses retrieved for the $\mathrm{D}$ day and the day before are based on updated analyses of meteorological fields.

GAS PHASE CHEMISTRY. Regarding the gas phase, CHIMERE uses a reduced mechanism (Derognat 2002) derived from the MELCHIOR chemical mechanism (Lattuati 1997); it includes 44 chemical species and about 120 reactions. MOCAGE takes into account 118 gaseous species and more than 350 chemical reactions, obtained by merging the Regional Atmospheric Chemistry Mechanism (RACM) tropospheric (Stockwell et al. 1997) and REPROBUS stratospheric (Lefèvre et al. 1994) chemical mechanisms and as described in Dufour et al. (2004).

Aerosols. Since the winter of 2004, aerosol forecasting has been implemented in CHIMERE. The particles are supposed to be made of anthropogenic primary particulate matter (PPM), sulfate, nitrate, ammonium, secondary organic aerosols (SOA), and wind-blown dust. The main modeled processes are described in Bessagnet et al. (2004). The current operational version of MOCAGE only accounts for dust particles from the African and Asian arid and semiarid regions (corresponding approximately to $93 \%$ of the total global emissions), based upon Marticorena and Bergametti (1995) and Laurent et al. (2006). The configuration, which uses five size bins, is evaluated in Martet et al. (2008, manuscript submitted to Tellus).

Input data. The CTMs used in the system require a number of input data: meteorological forcing, emissions, and boundary conditions (for CHIMERE, which is a regional CTM). While the system uses daily updated meteorological forecasts, which allow for biogenic emission calculation on a daily basis, anthropogenic emission data are updated every year, and chemical boundary conditions for CHIMERE are monthly climatologies.

Meteorological forecasts and analyses. As mentioned above, MOCAGE and CHIMERE do not produce their own meteorology but make use of data calculated offline by meteorological models. At global and European scales, MOCAGE uses the ARPEGE (Courtier et al. 1991) weather forecasts computed daily at Météo-France. Over the smaller domain (France), MOCAGE is forced by the ALADIN (Bubnova et al. 1995; Radnóti 1995) finer-scale forecasts.

CHIMERE uses a very different chain of weather forecast models: it is forced by mesoscale forecasts simulated with the fifth-generation Pennsylvania State University (PSU)-National Center for Atmospheric Research (NCAR) Mesoscale Model (MM5; Dudhia 1993), itself nudged into global analyses issued from the National Centers for Environmental Prediction (NCEP) using the Global Forecast System (GFS) weather forecast system. These daily forecasts are available, each day, online (www.nws.noaa.gov) and are retrieved automatically by the PREV'AIR system. MM5 is run locally at INERIS, at a resolution of about $36 \mathrm{~km}$ over a domain covering western Europe, and a resolution of about $18 \mathrm{~km}$ over France. It provides a number of necessary meteorological variables to CHIMERE: wind, temperature, humidity, surface fluxes, and boundary layer height.

EmISIION DATA. Anthropogenic emissions used by CHIMERE and MOCAGE over Europe are derived from the European Monitoring and Evaluation Programme (EMEP; cooperative program for monitoring and evaluation of the long range transmission of air pollutants in Europe, www.emep.int), which is carried out under the aegis of the Economic Commission for Europe of the United Nations (UNECE). The annual EMEP totals, provided by country or gridded with a low $50-\mathrm{km}$ resolution, are regridded 
onto the European model grids. Moreover, seasonal, weekly, and daily time profiles are applied in order to have hourly emissions variations. Outside of Europe, MOCAGE uses anthropogenic emissions from the Global Emissions Inventory Activity (GEIA) and Emission Database for Global Atmospheric Research (EDGAR) inventories, as proposed in Dentener et al. (2006).

Biogenic emissions of isoprene and terpenes are parameterized as fluxes following the approach described in Gunther (1997), and using the parameters and spatial distribution of vegetation methodology recommended in Simpson et al. (1999).

Boundary concentrations. At the European scale, the CHIMERE model uses climatological data (monthly means), computed with the LMDz-INCA global CTM (Hauglustaine et al. 2004) for a dozen of chemical gaseous species, among which are ozone, nitrogen dioxide, and nonmethane volatile organic compounds. For aerosols, the Goddard Chemistry Aerosol Radiation and Transport (GOCART; Ginoux et al. 2001) monthly means calculated for sulfate, elemental carbon, organic carbon, and dust concentrations are used. Over France, the CHIMERE model is then run in a one-way nested manner.

Some tests of using MOCAGE global timedependent outputs as chemical boundary conditions for CHIMERE are ongoing. The impact on CHIMERE skill scores will be assessed and the coupling of both models is currently envisioned as a possible upgrade for the system.

At the global scale, concentrations at the top boundary of the MOCAGE domain are prescribed from monthly climatologies. They have been obtained using the "climate chemistry" configuration of MOCAGE, which extends across the entire stratosphere and mesosphere and is described in Teyssèdre et al. (2007). The global MOCAGE domain provides the time-dependent chemical boundary conditions to the European and French domains, while a two-way nesting approach allows the zoom domains to feed back on the global domain.

ObSeRVATIOns. Observations obtained in near-real time are used to evaluate the performances of the system and to produce analyses by correcting ozone/PM10 simulations following an a posteriori process. In France, observations are provided by the local air quality monitoring networks, and gathered every $3 \mathrm{~h}$ at the national level to fill in the national nearreal-time air quality database (BASTER). These air quality data are retrieved automatically twice a day by PREV'AIR from the BASTER server, or even more often in case of a pollution episode. The system has been recently extended to German and Italian air quality networks, and new data form the United Kingdom, Finland, and Austria should be included in the analysis process in a near future.

Finally, historical sets of observations are used for implementing the so-called model output statistics (MOS) procedure presented below.

How does it work? The PREV'AIR system is based on several computational chains built upon the CHIMERE and MOCAGE models. However, the data provided on the public part of the Web site are issued from only one of them, considered by the PREV'AIR steering committee as the most relevant. This choice is reconsidered every 6 months, which means that PREV'AIR models and products can be updated with this frequency. The model configurations that are not selected as "official" ones by the steering committee are kept in test until the next upgrade of the platform.

Currently, the "official" PREV'AIR outputs are issues from the CHIMERE model configuration for the European and national scales, and from the MOCAGE model for the global scale.

As an example, daily cycle of operations in the PREV'AIR system for the CHIMERE forecasts/ analyses consist in a sequence of several tasks described below.

1) At about 1900 UTC of the day preceding the air quality forecasts availability (called day -1 ), NCEP meteorological forecasts are downloaded, and MM5 forecasts are produced. The forecasts are usually available at about 2100 UTC for the continental scale and 0200 UTC for the national domain. Meteorological forecasts run up to a lead time of day +2 , that is, three full days after the forecast has started.

2) Once meteorological forecasts are produced, the CTM air quality forecasts are calculated, first for the European-scale model version, and then for the nested finescale version. These pollutant forecasts are referred to as "raw outputs/products" in the following. The forecasts are usually available early in the morning of day +0 .

3) The French scale raw pollutant forecasts are then postprocessed using a statistical model in order to improve forecasts of ozone peaks concentrations. This statistical method is called the model output statistics (MOS) procedure. 
4) Ozone and PM10 analyses are produced for day -1 by correcting the simulation at day -1 by available observations that are retrieved from monitoring systems at the end of day -1 . The near-real-time observation data are further used to assess the performances of the system for the deterministic forecasts and the statistical approaches as well.

Figure 2 displays the sequence of actions taking place to derive this set of products. The entire forecast starts at 1900 UTC of day-1 and is completed in $5 \mathrm{~h}$.

MOCAGE simulations are sliced by day of forecasts and run on the operational chain of Météo-France. Day +0 , day +1 , and day +2 runs start, respectively, at 1510,1825 , and 2125 UTC of day -1 . One day of

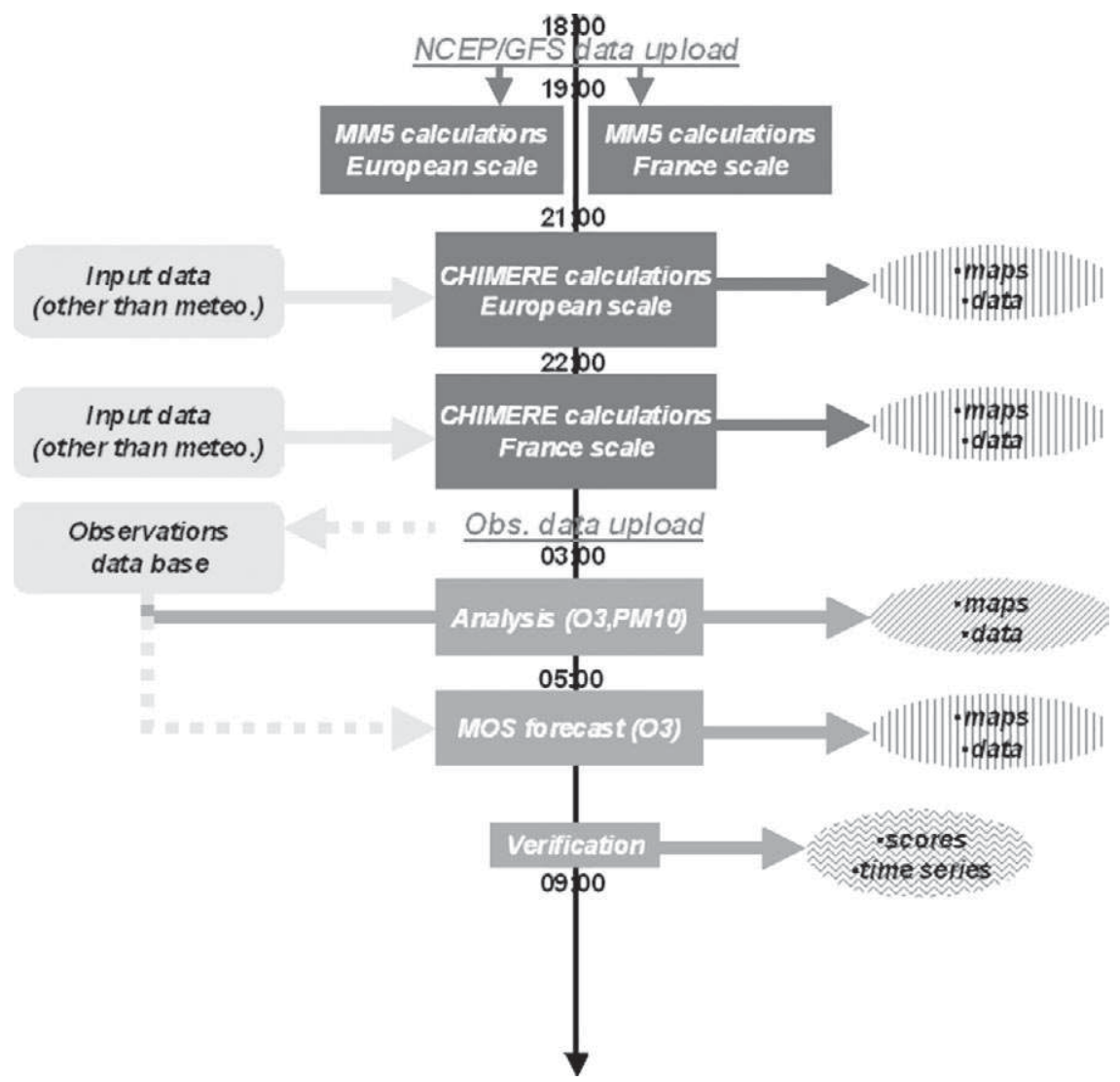

FIG. 2. Daily sequence of actions operated by the PREV'AIR system, for the European and France forecasts. Data upload and times (expressed as LST) are mentioned on the axis of the diagram, other input data are mentioned in light gray. Calculation modules stand in rectangles; output data are in circles. The links between input data, calculation modules, and output data are materialized by arrows. The sequence is initiated on the day-I evening, ends on day +0 morning, and generates deterministic and MOS forecasts for day +0 , day+I, and day+2; the analyses are generated for day-I; and skill scores are computed on the basis of all forecasts until day-I. Hours are expressed as "local time," and are indicative of the duration of the various PREV'AIR processes rather than the absolute time line. forecast by MOCAGE is completed in $3 \mathrm{~h}$. Fields are delivered to the PREV'AIR system as soon as they are available, all along the run.

At initial time, CHIMERE and MOCAGE use the result of the previous day's $24-\mathrm{h}$ forecast as initial conditions.

PREV'AIR PRODUCTS. Air quality forecasts. For the European and French domains, PREV'AIR system delivers everyday forecasts of ozone up to 2 days ahead, together with nitrogen dioxide and particulate matter (PM10 and PM2.5) concentrations forecasts. These outputs are made available on the PREV'AIR Web site early in the morning. Global-scale concentrations of ozone and nitrogen dioxide and dusts are also predicted up to 2 days ahead.

Note that the forecasted ozone concentration peaks in France are corrected before edition on the Web site following a MOS procedure. This approach aims at correcting simulated concentration fields taking into account the past model errors (differences between the simulation and the observation at measurement sites) in a statistical way. Model postprocessing techniques were first used for weather forecast, however, recent examples of application in the field of air quality forecasting can be found in some reports from the National Oceanic and Atmospheric Administration (information online at www.emc.ncep. noaa.gov/mmb/aq/docs/ kang_CMAS06.pdf) and in Monache et al. (2008). These methods estimate a model bias adjustment for a given time, considering the model error at some monitoring sites for the previous time steps. The approach used in PREV'AIR is based on historical records. A site-dependent regression model, trained over past 


\begin{tabular}{|c|c|c|c|c|c|c|c|c|c|}
\hline $\begin{array}{l}\text { Type of } \\
\text { stations }\end{array}$ & $\begin{array}{c}\text { Obs Peak } \\
\text { ozone } \\
\text { mean } \\
\left(\mu \mathrm{g} \mathrm{m}^{-3}\right)\end{array}$ & $\begin{array}{c}\text { Raw output } \\
\text { Peak ozone } \\
\text { mean } \\
\left(\mu \mathrm{g} \mathrm{m}^{-3}\right)\end{array}$ & $\begin{array}{c}\text { Bias } \\
\left(\mu \mathrm{g} \mathrm{m}^{-3}\right)\end{array}$ & $\begin{array}{c}\text { RMSE } \\
\left(\mu \mathrm{g} \mathrm{m}^{-3}\right)\end{array}$ & $\begin{array}{c}\text { Correlation } \\
\text { coef }\end{array}$ & $\begin{array}{c}\text { MOS output } \\
\text { Peak ozone } \\
\text { mean } \\
\left(\mu \mathrm{g} \mathrm{m}^{-3}\right)\end{array}$ & $\begin{array}{c}\text { Bias } \\
\left(\mu \mathrm{g} \mathrm{m}^{-3}\right)\end{array}$ & $\begin{array}{c}\text { RMSE } \\
\left(\mu \mathrm{g} \mathrm{m}^{-3}\right)\end{array}$ & $\begin{array}{c}\text { Correlation } \\
\text { ceof }\end{array}$ \\
\hline Rural & 108.9 & 106.4 & -2.5 & 19.5 & 0.83 & 111.2 & 2.3 & 18.0 & 0.86 \\
\hline Suburban & 106.3 & 105.8 & -0.5 & 18.8 & 0.85 & 109.0 & 2.7 & 18.6 & 0.86 \\
\hline Urban & 104.0 & 105.3 & 1.2 & 19.6 & 0.83 & 108.5 & 4.5 & 19.3 & 0.85 \\
\hline
\end{tabular}

data, is applied to forecast ozone peaks. The forecast error is regressed, at each monitoring site, from predicted 2-m temperature issues from MM5 forecast, and the predicted ozone daily maximum itself. This choice is motivated by a tendency of the model to underestimate high ozone concentration values found especially in hot summer spells. A different set of multiple regression coefficients is calculated for each site and each forecast lead time. Then, MOS daily maxima are calculated. The MOS forecasts issued for each monitoring station is then interpolated over the entire modeling domain by the same kriging method used for the analyses (see next section).

Table 1 illustrates the effect of the MOS procedure applied to the French domain in summer 2006. In that case the training periods were the summers of 2003-05. A rather significant improvement of the root-mean-square error $\left(18.0 \mu \mathrm{g} \mathrm{m}^{-3}\right.$ on average for rural stations obtained with the MOS procedure against $19.5 \mu \mathrm{g} \mathrm{m}^{-3}$ for raw model data) and the correlation factor $(0.86$ against 0.83 for raw data at rural

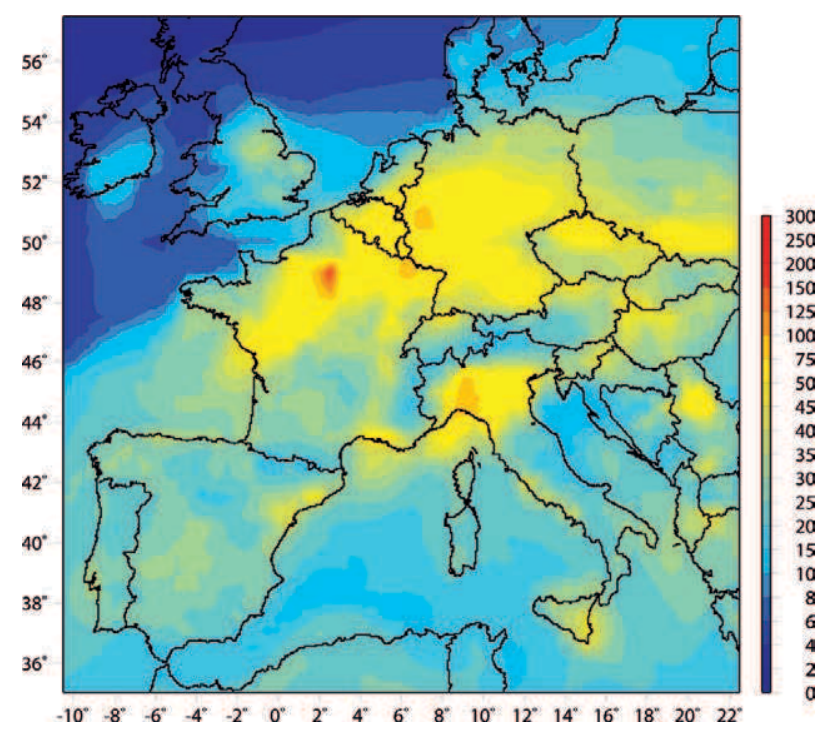

Fig. 3. I5 Mar 2007: day+I forecast of PMI0 peak concentrations in Europe. stations) is noted. For the prediction of the regulatory $180 \mu \mathrm{g} \mathrm{m}^{-3}$ threshold excedences the hit rate is improved by $10 \%-16 \%$, depending the type of site.

Figures 3-5 display different results issued from the PREV'AIR database. Figure 3 shows PM10 peak concentration forecasted on 15 March 2007 for the following day. This case was particularly interesting because it showed the development of an exceptional particulate matter episode in the western part of Europe. The model allowed for demonstration that the high PM concentrations were due to secondary compounds (ammonium nitrate, in that case), which has been confirmed by available measurements. PREV'AIR aided in understanding the secondary processes that led to the high concentrations recorded in that period.

Figures 4 and 5 are focused on ozone concentrations displayed at the European and global scales, respectively. The European map shows the day +2 peak concentrations predicted on 14 July 2006, during a heat wave that occurred at that time. The "informa-

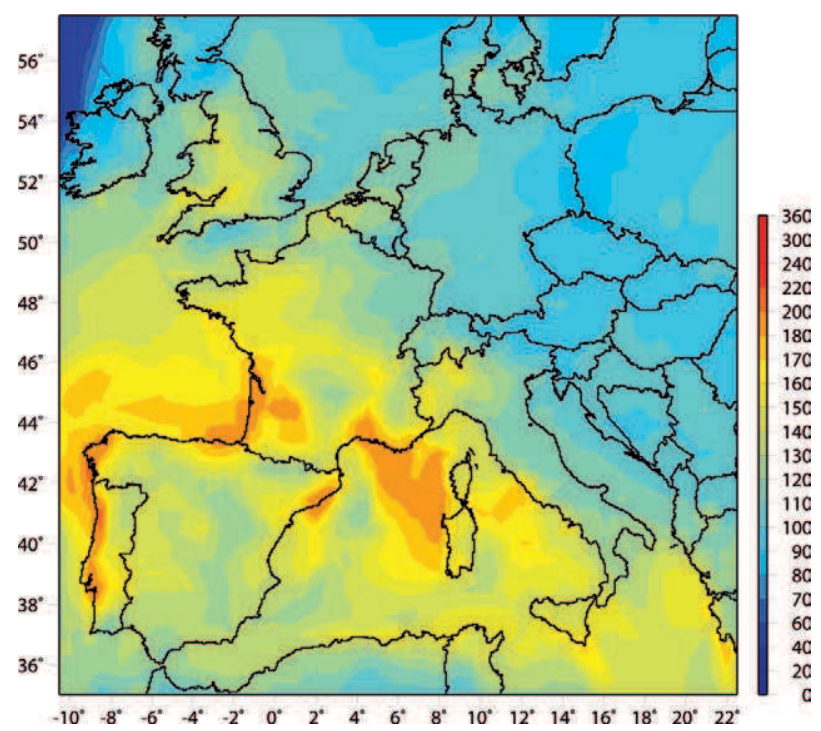

Fig. 4. I4 Jul 2006: day+2 forecast of ozone peak concentrations in Europe. 


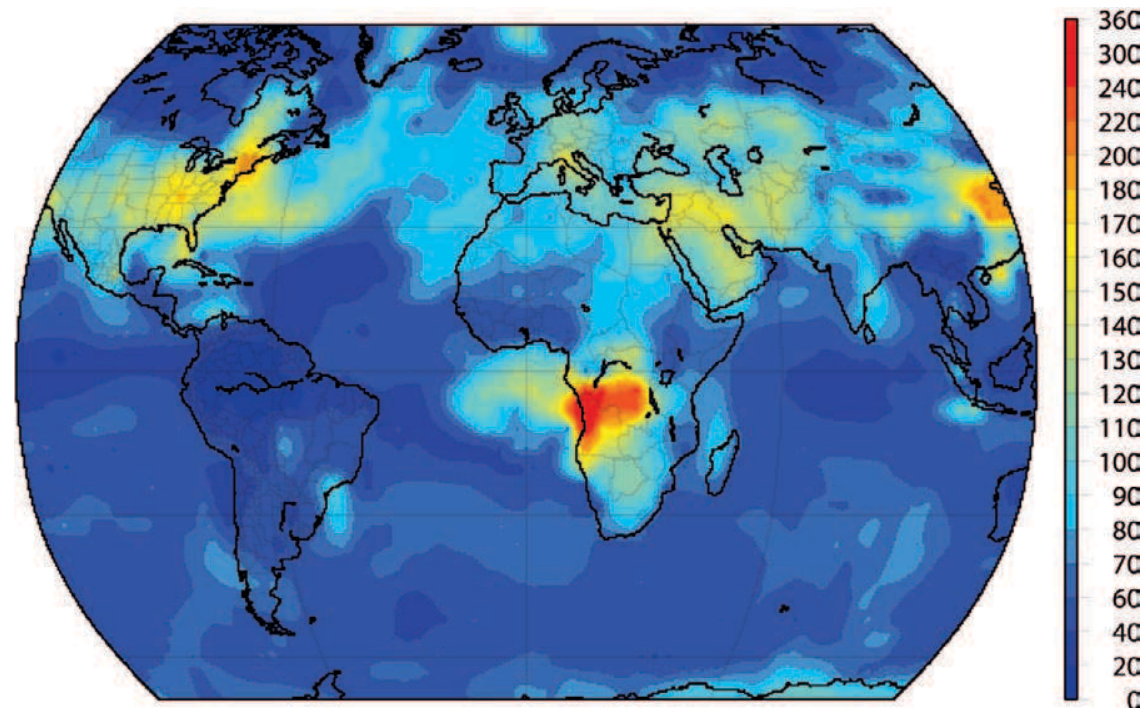

FIG. 5. 20 Jun 2007: global ozone peak concentrations predicted for the same day.

tion" regulatory threshold $\left(180 \mu \mathrm{g} \mathrm{m} \mathrm{m}^{-3}\right.$, according to the Directive 2002/03/EC of the European Parliament and of the council relating to ozone in ambient air) is exceeded in many southern areas. Measurements had confirmed the diagnostic provided by PREV'AIR. Figure 5 presents ozone peak concentrations predicted on 20 June 2007 for the current day. High ozone levels in Africa resulting from biomass burning appear clearly and are regularly observed. Although it was early summer, very low levels of ozone in Western Europe are noted, because of exceptionally low temperatures.

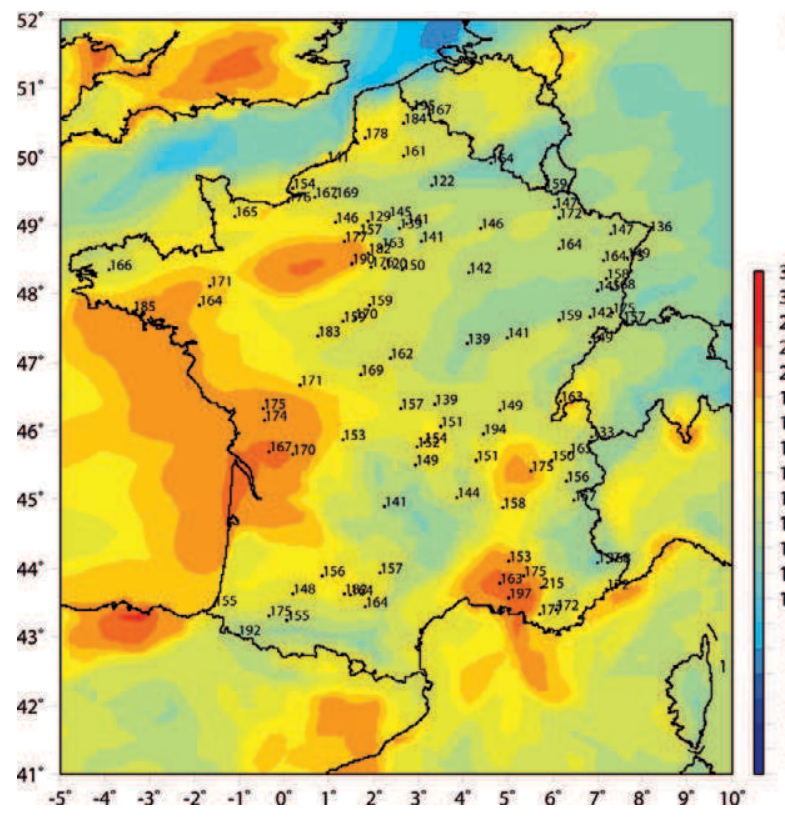

Air quality analyses and nearreal-time database. Analyses are produced every day for the day before, using day -1 simulations corrected by surface observations. This option is fully operational at the French scale thanks to the near-realtime air quality monitoring BASTER database. Other European air quality monitoring agencies should also deliver data to the system for analyses in the near future, enabling the extension of analyses to Europe. The methodology to yield analyzed fields is based on a simple kriging of the model simulation error found at monitoring station points. The kriged residual is then added to the simulation to form an observation-corrected field-the analysis. Figure 6 shows an example of the results obtained for France on 17 July 2006. Significant changes in ozone patterns and concentration levels are found between the simulation and the simulation corrected by observations, especially in complex areas such as the Mediterranean side of the country. The measured concentrations appear explicitly on the map and show that ozone concentrations were generally underestimated by the

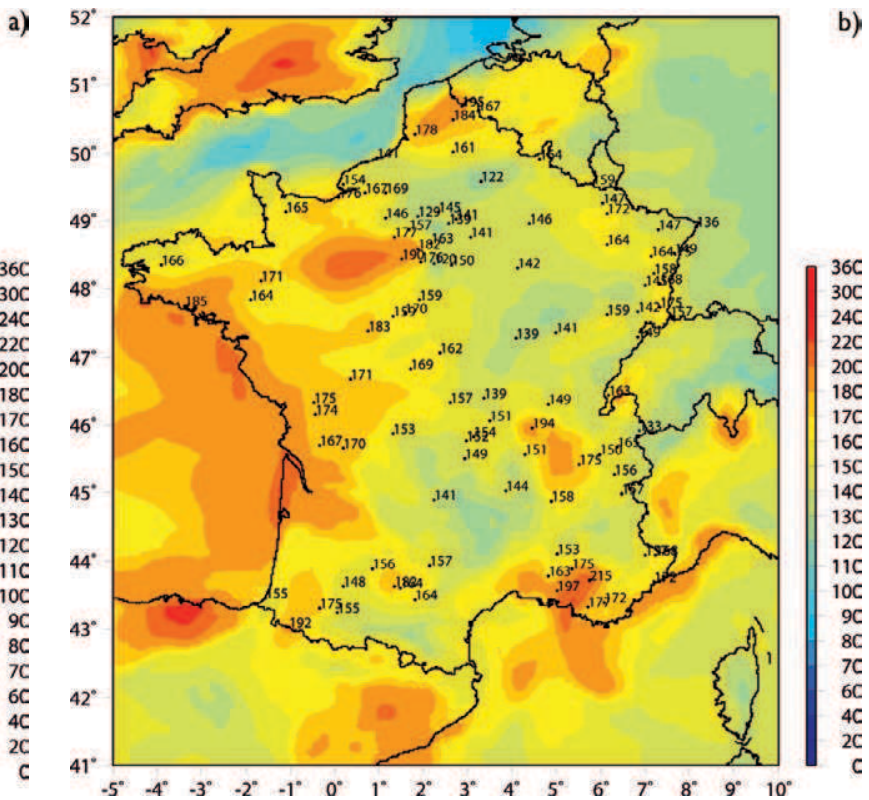

FIg. 6. 17 Jul 2006: (a) ozone peak concentrations simulated by the CHIMERE model in the PREV'AIR system; observations are included as numbers. (b) Analyzed ozone peak concentrations are also shown. 
model (Fig. 6a). However, the correction is more significant in the eastern part of the country (Fig. 6b). In any case, ozone patterns are quite similar for both maps.

Analyzed maps, considered as the most realistic representation of pollution fields, are used by policy makers to establish seasonal budgets and to assess the effects of emission control measures.

Evaluation scores. The forecasts are evaluated every year using an exhaustive comparison between observations and forecasts. Statistical indicators such as bias, root-mean-square errors, and correlation coefficients are computed for each species. An extensive analysis of these results is proposed in a companion paper (Honoré et al. 2008). In this study, the evaluation is made using French air quality observations, but also data from other countries (Belgium, the Czech Republic, Germany, the Netherlands, Switzerland, and the United Kingdom for ozone; Belgium, Germany, and the Netherlands for PM10). The evaluation is made over three consecutive summers of operational forecasts. It is demonstrated that the PREV'AIR system performances comply with the state of the art, as established in previous model intercomparison studies (Vautard et al. 2006; Van Loon et al. 2007). The scores are particularly satisfactory for ozone peak prediction as illustrated in Table 2. Rootmean-square errors (RMSE) vary, on average, from about $17 \mu \mathrm{g} \mathrm{m}^{-3}$ at day -1 (simulation of the previous day) to about $20 \mu \mathrm{g} \mathrm{m}^{-3}$ at day +2 , which remains less than $25 \%$ of the average concentrations. Correlation decreases from 0.84 to 0.76 . The bias remains small.

These skill scores are found, for ozone, among the best ones when compared to that of other models, as demonstrated in Van Loon et al. (2007).

CONCLUSIONS AND PERSPECTIVE. The operational air quality forecasting and analysis system PREV'AIR has been presented in this paper. This system provides real-time information about air pollutant concentrations throughout Europe, with a focus on France, which is particularly relevant to health prevention in acute pollution episodes. Such pollution events occur several times a year in western Europe, explaining the rise of concern of the health community for their prediction. This is a user-oriented system: a large amount of information is proposed to the public (maps, scores) and more data can be provided on users' accounts (three-dimensional fields, especially). The potential interest of PREV'AIR abilities for communities dealing with air quality has been discussed and illustrated with examples. Air quality forecasting and mapping is an efficient tool for authorities in charge of air quality management. Anticipating pollution events with concentrations exceeding regulatory levels allows them to inform the general public and to decide emergency control measures. Thereby, the health community can deal more easily with sensitive populations. PREV'AIR has now become a part of the French air quality monitoring system. Finally, such a system providing routinely forecasts, analyzed maps, and scores helps in understanding model behavior, interpreting air pollution events, and improving scientific knowledge. 
Its results are carefully evaluated and scores are presented on the Web site in a transparent way. This allows the user to build confidence in the system. All results computed by the PREV'AIR system since 2003 are archived in a simulation database with results easily available. This is a precious data source for the interpretation of trends and compliance checking with regulatory purposes.

The structure of the project gathers the experience of four organizations playing an identified role relevant to their skills. The PREV'AIR consortium involves researchers in the atmospheric sciences for air quality modeling, scientists in the meteorological sciences, engineers in charge of operational implementation, and other staff dealing with national and local organizations for a policy point of view. Lessons learned from a day-by-day score analysis are taken into account to improve each part of the system.

This fruitful organization leads to an original and stable system, which will be promoted in the Global Monitoring for Environment and Security (GMES) initiative, the Global Earth Observation System of Systems (GEOSS) European component. The European Commission has recently launched an ambitious program devoted to the implementation of operational services based on atmospheric composition monitoring, within the framework of GMES, the GMES Atmospheric Service (GAS), dedicated to the implementation of operational services for atmospheric composition monitoring. PREV'AIR, being one of the most achieved and advanced European systems dedicated to air pollutant monitoring and forecasting and because of its open capacity, will contribute to the implementation of a significant component of the GAS for air quality.

Public and policy makers' interest for air quality should increase in the coming years considering the remaining necessary efforts to reduce population exposure and ecosystem damage resulting from air pollution. Definitively, operational systems devoted to air quality forecasting and near-real-time analysis provide a significant opportunity to deal with the management of air pollution allowing anticipation and widely accessible information throughout largescale territories.

ACKNOWLEDGMENTS. The French Ministry in charge of Ecology and Sustainable Development is kindly acknowledged for its support and funding for the development and implementation of the PREV'AIR system.

\section{REFERENCES}

Bessagnet, B., A. Hodzic, R. Vautard, M. Beekmann, S. Cheinet, C. Honoré, C. Liousse, and L. Rouil, 2004: Aerosol modeling with CHIMERE-Preliminary evaluation at the continental scale. Atmos. Environ., 38, 2803-2817.

Bubnova, R., G. Hello, P. Bénard, and J.-F. Geleyn, 1995: Integration of the fully-elastic equations cast in the hydrostatic pressure terrain-following coordinate in the framework of the ARPEGE/ALADIN NWP system. Mon. Wea. Rev., 123, 515-535.

Courtier, P., C. Freydiet, J.-F. Geleyn, F. Rabier, and M. Rochas, 1991: The Arpege project at Météo France. Proc. Numerical Methods in Atmospheric Models, Reading, United Kingdom, European Centre for Medium-Range Weather Forecasts, 193-231.

Dentener, F., and Coauthors, 2006: The global atmospheric environment for the next generation. Environ. Sci. Technol., 40, 3586-3594.

Derognat, C., 2002: Pollution photooxydante à l'échelle urbaine et interaction avec l'échelle regionale. Ph.D. thesis, Université Paris VI, 273 pp.

Dudhia, J., 1993: A nonhydrostatic version of the Penn State/NCAR mesoscale model: Validation tests and simulation of an Atlantic cyclone and cold front. Mon. Wea. Rev., 121, 1493-1513.

Dufour, A., M. Amodei, G. Ancellet, and V. H. Peuch, 2004: Observed and modeled "chemical weather" during ESCOMPTE. Atmos. Res., 74 (1-4), 161-189.

Eder, B., D. Kang, R. Mathur, S. Yu, and K. Schere, 2006: An operational evaluation of the Eta-CMAQ air quality forecast model. Atmos. Environ., 40, 4894-4905.

Ginoux, P., M. Chin, I. Tegen, J. M. Prospero, B. Holben, O. Dubovik, and S.-J. Lin, 2001: Sources and distributions of dust aerosols simulated with the GOCART model. J. Geophys. Res., 106, 20 255-20 273.

Gunther, A., 1997: Seasonal and spatial variations in natural volatile organic compound emissions. Ecol. Appl., 7, 34-45.

Hauglustaine, D. A., F. Hourdin, L. Jourdain, M. A. Filiberti, S. Walters, J. F. Lamarque, and E. A. Holland, 2004: Interactive chemistry in the Laboratoire de Météorologie Dynamique general circulation model: Description and background tropospheric chemistry evaluation. J. Geophys. Res., 109, D04314, doi:10.1029/2003JD003957.

Honoré, C., and Coauthors, 2008: Predictability of regional air quality in Europe: Assessment of three years of operational forecasts and analyses over Europe. J. Geophys. Res., 113, D04301, doi:10.1029/2007JD008761. 
Lattuati, M., 1997: Impact des émissions Européennes sur le bilan d'ozone troposhérique à l'interface de l'Europe et de l'Atlantique Nord: Apport de la modélisation lagrangienne et des mesures en altitude. Ph.D. thesis, Université P\&M Curie, 217 pp.

Laurent, B., B. Marticorena, G. Bergametti, and G. Mei, 2006: Modeling mineral dust emissions from Chinese and Mongolian deserts. Global Planet. Changes, 52, 121-141.

Lefèvre, F., G. P. Brasseur, I. Folkins, A. K. Smith, and P. Simon, 1994: Chemistry of the 1991-1992 stratospheric winter: Three-dimensional model simulations. J. Geophys. Res., 99 (D4), 8183-8195.

Marticorena, B., and G. Bergametti, 1995: Modeling the atmospheric dust cycle: 1-Design of a soil derived dust production scheme. J. Geophys. Res., 100, 16 415-16 430 .

McKeen, S., and Coauthors, 2005: Assessment of an ensemble of seven real-time ozone forecasts over eastern North America during the summer of 2004. J. Geophys. Res., 110, D21307, doi:10.1029/2005JD005858.

Monache, L. C., J. Wilczak, S. McKeen, G. Grell, M. Pagowski, S. Peckham, R. Stull, J. McHenry, and J. McQueen, 2008: A Kalman-filter bias correction method applied to deterministic, ensemble averaged and probabilistic forecasts of surface ozone. Tellus, 60B, 238.

Otte, T. L., and Coauthors, 2005: Linking the Eta Model with the Community Multiscale Air Quality (CMAQ) Modeling System to build a national air quality forecasting system. Wea. Forecasting, 20, 367-384.

Parodi, S., M. Vercelli, E. Garrone, V. Fontana, and A. Izzotti, 2005: Ozone air pollution and daily mortality in Genoa, Italy between 1993 and 1996. Public Health, 119, 844-850.

Peuch, V.-H., M. Amodei, T. Barthet, M.-L. Cathala, B. Josse, M. Michou, and P. Simon, 1999: MOCAGE, Modèle de Chimie Atmosphérique à Grande Echelle. Proc. Météo-France Workshop on Atmospheric Modelling, Toulouse, France, Météo-France, 33-36.

Radnóti, G., 1995: A spectral limited-area formulation with time-dependant boundary conditions applied to the shallow-water equations. Mon. Wea. Rev., 123, 3122-3123.
Schlink, U., O. Herbarth, M. Richter, S. Dorling, G. Nunnari, G. Cawley, and E. Pelikan, 2006: Statistical models to assess the health effects and to forecast ground-level ozone. Environ. Modell. Software, 21, 547-558.

Schmidt, H., C. Derognat, R. Vautard, and M. Beekmann, 2001: A comparison of simulated and observed ozone mixing ratios for the summer of 1998 in Western Europe. Atmos. Environ., 35, 6277-6297.

Stedman, J. R., 2005: The predicted number of air pollution related deaths in the UK during the August 2003 heatwave. Atmos. Environ., 38, 1087-1090.

Stockwell, W. R., F. Kirchner, M. Kuhn, and S. Seefeld, 1997: A new mechanism for regional atmospheric chemistry modeling. J. Geophys. Res., 102, 25 847-25 879.

Teyssèdre, H., and Coauthors, 2007: A new tropospheric and stratospheric Chemistry and Transport Model MOCAGE-Climat for multi-year studies: Evaluation of the present-day climatology and sensitivity to surface processes. Atmos. Chem. Phys., 7, 5815-5860.

Tilmes, S., and Coauthors, 2002: Comparison of five Eulerian air pollution forecasting systems for the summer of 1999 using the German ozone monitoring data. J. Atmos. Chem., 42, 91-121.

Van Loon, M., and Coauthors, 2007: Evaluation of long-term ozone simulations from seven regional air quality models and their ensemble average. Atmos. Environ., 41, 2083-2097.

Vautard, R., M. Beekmann, J. Roux, and D. Gombert, 2001: Validation of a hybrid forecasting system for the ozone concentrations over the Paris area. Atmos. Environ., 35, 2449-2461.

—, C. Honoré, M. Beekmann, and L. Rouil, 2005: Simulation of ozone during the August 2003 heat wave and emission control scenarios. Atmos. Environ., 39, 2957-2967.

— parison of ozone and PM10 simulations by several chemistry-transport models over 4 European cities within the City-Delta project, Atmos. Environ., 41, 173-188.

WHO, 2005: Health and climate change: The "now and how." A policy action guide. World Health Organization Report, 35 pp. [Available online at www. whcaonline.org/uploads/publications/Climate $\% 20$ Change.pdf.] 